\title{
Epithelial-mesenchymal transition phenotype of circulating tumor cells is associated with distant metastasis in patients with NSCLC
}

\author{
XIAOCHEN ZHANG ${ }^{1 *}$, LIYUAN WEI $^{1 *}$, JUN LI $^{2}$, JING ZHENG $^{3}$, SHIRONG ZHANG $^{4}$ and JIANYING ZHOU ${ }^{3}$ \\ Departments of ${ }^{1}$ Medical Oncology and ${ }^{2}$ Pathology, The First Affiliated Hospital, College of Medicine, \\ Zhejiang University; ${ }^{3}$ Department of Respiratory Disease, Thoracic Disease Centre, The First Affiliated Hospital, \\ College of Medicine, Zhejiang University, Hangzhou, Zhejiang 310000; ${ }^{4}$ Department of Oncology, \\ Hangzhou First People's Hospital, Hangzhou, Zhejiang 310006, P.R. China
}

Received March 11, 2018; Accepted October 24, 2018

DOI: $10.3892 / \mathrm{mmr} .2018 .9684$

\begin{abstract}
Circulating tumor cells (CTCs) are closely associated with cancer metastasis in preclinical models and patients with cancer. However, to the best of the authors knowledge, it remains unknown which type of CTCs may serve the key role in cancer metastasis. The present study investigated the association between the epithelial-mesenchymal transition (EMT) phenotype of CTCs from the peripheral blood and distant metastasis in patients with non-small cell lung cancer (NSCLC). Expression of EMT markers in CTCs from a cohort of patients was detected using Canpatrol ${ }^{\mathrm{TM}} \mathrm{CTC}$ assays. A total of 110 patients (85 patients with NSCLC and 25 patients with benign diseases) were recruited. Among the 110 patients, $88(80.0 \%)$ were characterized as CTC positive with EMT markers. Receiver operating characteristic curves revealed that $\mathrm{E}^{+} / \mathrm{M}^{+} \mathrm{CTC}$ exhibited the highest area under the curve (AUC) value of 0.876 [95\% confidence interval (CI), 0.805-0.948; $\mathrm{P}<0.001)$ in distinguishing between patients with NSCLC and benign pulmonary diseases, and $\mathrm{M}^{+} \mathrm{CTC}$ had the highest AUC value of 0.723 (95\% CI, 0.612-0.833; $\mathrm{P}<0.001)$ in differentiating patients with NSCLC with distant metastasis from those with
\end{abstract}

Correspondence to: Dr Jianying Zhou, Department of Respiratory Disease, Thoracic Disease Centre, The First Affiliated Hospital, College of Medicine, Zhejiang University, 79 Qingchun Road, Shangcheng, Hangzhou, Zhejiang 310000, P.R. China

E-mail: zjyhz@zju.edu.cn

Dr Shirong Zhang, Department of Oncology, Hangzhou First People's Hospital, 261 Huansha Road, Shangcheng, Hangzhou, Zhejiang 310006, P.R. China

E-mail: shirleyz4444@163.com

*Contributed equally

Abbreviations: EMT, epithelial-mesenchymal transition; CTCs, circulating tumor cells; NSCLC, non-small cell lung cancer; $\mathrm{ROC}$, receiver operating characteristic; AUC, area under the curve

Key words: circulating tumor cell, non-small cell lung cancer, epithelial-mesenchymal transition, distant metastasis non-distant metastasis. The results indicate the potential predictive value of distant metastasis of the EMT phenotype of CTCs in the peripheral blood of patients with NSCLC.

\section{Introduction}

Lung cancer is a type of cancer that causes the highest number of cancer-associated mortalities in men and women globally, accounting for $26 \%$ of all cancer mortalities in men and $25 \%$ in women in 2018 (1). The numbers of novel cases and mortalities due to lung cancer were estimated to be 234,030 and 154,050, respectively, in the United States in 2018 (1). In China, there were $\sim 700,000$ novel cases of lung cancer and $\sim 600,000$ lung cancer-associated mortalities in 2015 (2). Among patients with lung cancer, $>50 \%$ are diagnosed with metastatic disease and the five-year survival rate is $<5 \%$ (3). Although the development of novel targeted therapies based on the predictive biomarkers of lung cancer have markedly improved the clinical outcome, it remains poor considering the extensive invasion, recurrence and the metastasis of non-small cell lung cancer (NSCLC) (4). Accumulating evidence suggests that although patients with identical histology, differentiation, location and stage of diagnosis receive similar therapy, the survival of these patients is heterogeneous. This indicates that the current methods of tumor classification and staging are insufficient for selecting the most appropriate treatment (5). Therefore, the development of novel biomarkers that accurately predict patients at greatest risk of metastasis is essential in order to select the appropriate treatment strategy in order to increase the survival rate.

In NSCLC, circulating tumor cells (CTCs) have been used as a prognostic, predictive and pharmacodynamic biomarker $(6,7)$. The characterization of CTCs may identify the mechanism of metastasis (8). In general, tumor dissemination includes a number of steps, including: The generation of invasive subpopulations of tumor cells, dissolution of the stroma, transport into the peripheral circulation or lymphatic system, establishment at a secondary lesion at a novel site and angiogenesis (9). CTCs may be discharged into the blood circulation at an earlier stage compared with the metastasis of cancer and may be detected in the early stage of cancer development (10). In these invasive tumor cells, the epithelial-mesenchymal transition (EMT) is a key process in metastasis for the 
progression of cancer, including in NSCLC (4) and is considered to be an initiating event for distant dissemination $(5,11)$. Previous studies have also revealed that EMT is associated with chemotherapeutic resistance $(12,13)$. Epithelial markers including epithelial cell adhesion molecule (EpCAM) and cytokeratins (CKs) have been demonstrated to be downregulated and mesenchymal markers including vimentin and twist family BHLH transcription factor 1 (TWIST1) have been demonstrated to be upregulated (14-16). Therefore, CTCs in the initial stages of dissemination are assumed to express the EMT phenotype. Detection of the EMT changes of CTCs may aid the identification of the aggressive behavior of NSCLC.

The Canpatrol ${ }^{\mathrm{TM}}$ CTC assay classifies CTCs into epithelial, bi-phenotypic (epithelial and mesenchymal) and mesenchymal subtypes by using a cocktail of epithelial (EpCAM and CK8/18/19) and mesenchymal (vimentin and TWIST1) markers $(14,17)$. In the present study, the EMT phenotypes of CTCs isolated from the peripheral blood samples of a cohort of patients with NSCLC were characterized using the Canpatrol $^{\text {TM }}$ CTC technique.

\section{Patients and methods}

Patient enrollment and blood collection. The present study was ethically approved by the Ethics Committee of the First Affiliated Hospital of Zhejiang University (Hangzhou, China). A total of 85 NSCLC patients and 25 benign patients were enrolled in the study between December 2016 and June 2018 and written informed consent was obtained from the patients prior to their enrollment. The patients who were pathologically diagnosed with NSCLC without any history of other types of malignant cancer were recruited into the NSCLC cohort, and the patients who were clinically diagnosed with benign lung disease were in the benign cohort. Patients aged $\leq 18$ years old were excluded. In NSCLC cohort, there were 53 males and 32 females. The median age of the patients was 63 years old with the range between 32 and 83 . All the NSCLC patients were classified into groups with and without distant metastasis according to the 8th edition of the American Joint Committee on Cancer tumor-node-metastasis staging system for lung cancer (18). Peripheral blood samples $(5 \mathrm{ml})$ from 85 patients with NSCLC were collected in EDTA tubes by venipuncture and stored at $4^{\circ} \mathrm{C}$ until cell isolation, which was performed within $4 \mathrm{~h}$. The blood samples were collected prior to surgery, radiation therapy and chemotherapy from patients with NSCLC of different stages. Peripheral blood samples were also collected from 25 patients with benign diseases, of which 2 patients presented with granuloma, 2 were pseudotumor, 4 were pulmonary nodule and 17 were tuberculosis.

Isolation and classification of CTCs. CTCs were isolated and classified using a Canpatrol ${ }^{\text {TM }}$ CTC assay (SurExam, Guangzhou, China; http://www.surexam.com/) as previously described (14). Briefly, erythrocyte lysis buffer, provided in the assay kit, was added to the peripheral blood samples within $4 \mathrm{~h}$ of venipuncture and incubated for $30 \mathrm{~min}$ at room temperature. The blood samples were then filtered using an $8-\mu \mathrm{m}$ diameter pore-calibrated membrane (EMD Millipore, Billerica, MA, USA) in order to collect the CTCs. The enriched CTCs were subjected to RNA in situ hybridization with a combination of epithelial (EpCAM and CK8/18/19) and mesenchymal (vimentin and TWIST1) markers (provided in the assay kit). The CTCs were then stained with a concentration of 4',6-diamidino-2-phenylindole (Sigma-Aldrich; Merck $\mathrm{KGaA}$, Darmstadt, Germany) at $100 \mathrm{ng} / \mathrm{ml}$ for $5 \mathrm{~min}$ at room temperature and analyzed with an automated imaging fluorescent microscope (Carl Zeiss AG, Oberkochen, Germany). The CTCs of each patient were classified based on the identification of the markers. The Canpatrol ${ }^{\mathrm{TM}} \mathrm{CTC}$ assay protocol is described in a previously published study (17). Briefly, CTCs were classified into three subpopulations according to epithelial and mesenchymal markers that they expressed, including epithelial CTCs ( $\left.\mathrm{E}^{+} \mathrm{CTCs}\right)$, biophenotypic epithelial/mesenchymal CTCs $\left(\mathrm{E}^{+} / \mathrm{M}^{+} \mathrm{CTCs}\right)$, and mesenchymal CTCs $\left(\mathrm{M}^{+}\right.$ CTCs). $\mathrm{E}^{+} \mathrm{CTC}$ refer to the cells that predominantly express EpCAM and/or CK8/18/19 but do not express CD45; M $^{+}$CTCs mainly express vimentin and/or TWIST markers but not CD45; and $\mathrm{E}^{+} / \mathrm{M}^{+} \mathrm{CTC}$ express epithelial and mesenchymal markers but not CD45.

Statistical analysis. The Mann-Whitney U test was used to compare the EMT phenotype of CTCs from patients of different subgroups for non-normally distributed data. Comparisons of the rate between each subgroup were tested using $\chi^{2}$ and Fisher's exact tests. Receiver operating characteristic (ROC) curves and the area under the curve (AUC) were determined in order to assess the predictive and diagnostic power of different types of CTC subset. The optimal cut-off value of every subset was selected using the Youden index (19), which represents the threshold value when the following is maximal: Sensitivity + specificity-1. The statistical analyses were two-sided and $\mathrm{P}<0.05$ was considered to indicate a statistically significant difference. Statistical analysis was conducted using SPSS software, version 22.0 (IBM Corp., Armonk, NY, USA). The measured data of CTCs was presented as mean \pm standard deviation. The age of patients was presented as median (range).

\section{Results}

Patient characteristics. In the 85 NSCLC patients, $61.2 \%$ had a history of smoking. The type of NSCLC was predominantly adenocarcinoma (67.1\%; Table I). In total, $18.8 \%$ of patients were diagnosed with stage I disease, $15.3 \%$ were stage II, $17.6 \%$ were stage III and $48.2 \%$ were stage IV. The assessment of distant metastasis was determined according to the Tumor-Node-Metastasis staging system based on clinical analysis, radiography and histology. Among the 85 patients with NSCLC, 41 patients exhibited distant metastasis (M1) and 44 patients presented no distant metastasis (M0). Peripheral blood samples were also collected from 17 men and 8 women (age range, 41-70 years) with benign diseases including interstitial pneumonia and benign small pulmonary nodules.

EMT phenotypes of total CTCs from patients with NSCLC and benign pulmonary diseases. The EMT phenotypes of CTCs were analyzed in blood samples isolated from 85 (77.3\%) patients with NSCLC and 25 (22.7\%) patients with benign pulmonary diseases. Among the 110 patients recruited, $88(80.0 \%)$ patients were characterized as CTC positive 
Table I. Characterization of CTCs in patients with NSCLC.

\begin{tabular}{|c|c|c|c|c|c|c|c|}
\hline Parameters & $\begin{array}{l}\text { Total patients } \\
\qquad(\mathrm{n}=110)\end{array}$ & $\begin{array}{l}\text { Benign } \\
(n=25)\end{array}$ & $\begin{array}{l}\text { NSCLC } \\
(n=85)\end{array}$ & P-value & M0 patient & M1 patient & P-value \\
\hline Age (years), median (range) & $63(32-83)$ & $63(41-70)$ & $63(32-83)$ & $>0.05$ & $63(47-83)$ & $63(32-83)$ & $>0.05$ \\
\hline Male \% (n) & $63.6(70 / 110)$ & $68.0(17 / 25)$ & $62.4(53 / 85)$ & $>0.05$ & $63.6(28 / 44)$ & $61.0(25 / 41)$ & $>0.05$ \\
\hline Smoking history \% (n) & $60.9(67 / 110)$ & $60.0(15 / 25)$ & $61.2(52 / 85)$ & $>0.05$ & $61.4(27 / 44)$ & $60.9(25 / 41)$ & $>0.05$ \\
\hline Adenocarcinoma \% (n) & - & - & $67.1(57 / 85)$ & $>0.05$ & $56.8(25 / 44)$ & $53.7(22 / 41)$ & $>0.05$ \\
\hline \multicolumn{8}{|l|}{ Total CTCs } \\
\hline$\geq 1$ cell/5 ml blood $\%(n)$ & $81.1(77 / 95)$ & $60.0(15 / 25)$ & $85.9(73 / 85)$ & $<0.05$ & $81.8(36 / 44)$ & $90.2(37 / 41)$ & $>0.05$ \\
\hline Range & $0-57$ & $0-2$ & $0-57$ & & $0-17$ & $0-57$ & \\
\hline Median & 4 & 1 & 5 & & 4 & 7 & \\
\hline Mean \pm SD & $6.47 \pm 7.80$ & $0.84 \pm 0.80$ & $7.16 \pm 7.90$ & $<0.001$ & $5.66 \pm 5.16$ & $8.78 \pm 9.97$ & $>0.05$ \\
\hline \multicolumn{8}{|l|}{$\mathrm{E}^{+} \mathrm{CTCs}$} \\
\hline$\geq 1$ cell/5 ml blood $\%(\mathrm{n})$ & $64.2(61 / 95)$ & $60.0(15 / 25)$ & $67.1(57 / 85)$ & $>0.05$ & $59.1(26 / 44)$ & $75.6(31 / 41)$ & $>0.05$ \\
\hline Range & $0-12$ & $0-2$ & $0-12$ & & $0-12$ & $0-9$ & \\
\hline Median & 2 & 1 & 2 & & 2 & 2 & \\
\hline Mean \pm SD & $2.27 \pm 2.61$ & $0.84 \pm 0.80$ & $2.47 \pm 2.67$ & $<0.05$ & $2.5 \pm 3.03$ & $2.43 \pm 2.26$ & $>0.05$ \\
\hline \multicolumn{8}{|l|}{$\mathrm{E}^{+} / \mathrm{M}^{+} \mathrm{CTCs}$} \\
\hline$\geq 1$ cell $/ 5 \mathrm{ml}$ blood $\%(\mathrm{n})$ & $67.4(64 / 95)$ & $0(0 / 25)$ & $75.3(64 / 85)$ & $<0.05$ & $72.7(32 / 44)$ & $73.2(30 / 41)$ & $>0.05$ \\
\hline Range & $0-45$ & 0 & $0-45$ & & $0-10$ & $0-45$ & \\
\hline Median & 2 & 0 & 2 & & 2 & 2 & \\
\hline Mean \pm SD & $3.16 \pm 5.75$ & $0.00 \pm 0.00$ & $3.53 \pm 5.97$ & $<0.001$ & $2.63 \pm 2.69$ & $4.48 \pm 8.08$ & $>0.05$ \\
\hline \multicolumn{8}{|l|}{$\mathrm{M}^{+} \mathrm{CTCs}$} \\
\hline$\geq 1$ cell $/ 5 \mathrm{ml}$ blood $\%(\mathrm{n})$ & $40.0(38 / 95)$ & $0(0 / 25)$ & $44.7(38 / 85)$ & $<0.05$ & $25.0(11 / 44)$ & $65.8(27 / 41)$ & $<0.001$ \\
\hline Range & $0-10$ & 0 & $0-10$ & & $0-5$ & $0-10$ & \\
\hline Median & 0 & 0 & 0 & & 0 & 1 & \\
\hline Mean \pm SD & $1.04 \pm 1.76$ & $0.00 \pm 0.00$ & $1.16 \pm 1.83$ & $<0.001$ & $0.52 \pm 1.15$ & $1.85 \pm 2.15$ & $<0.001$ \\
\hline
\end{tabular}

CTCs, circulating tumor cells; NSCLC, non-small cell lung cancer; SD, standard deviation; $\mathrm{E}^{+}$, epithelial expressing; $\mathrm{M}^{+}$, mesenchymal expressing.

with EMT markers ( $\geq 1$ cell/5 $\mathrm{ml}$ blood) using a Canpatrol ${ }^{\mathrm{TM}}$ CTC assay (Fig. 1A). Representative images of the different phenotypic CTCs are shown in Fig. 1B.

The total number of CTCs in patients with benign pulmonary diseases (mean, $0.84 \pm 0.80$; median, 1.00) was lower compared with that of patients with NSCLC (M0: mean,

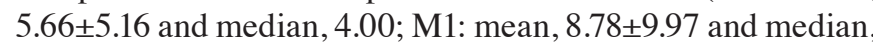
7.00). The difference in the total number of CTCs between patients with benign pulmonary diseases and NSCLC was statistically significant $(\mathrm{P}<0.001)$, while that between M0 and M1 was not (Fig. 1A).

The CTC-positive rate in patients with benign pulmonary diseases, NSCLC, non-distant metastatic NSCLC (M0), and distant metastatic NSCLC (M1) was 60.0 (15/25), $85.9(73 / 85)$, 81.8 (36/44) and 90.2\% (37/41), respectively (Fig. 2; Table I). The difference in the CTC-positive rate between patients with benign pulmonary diseases and NSCLC was statistically significant $(\mathrm{P}<0.05)$, while that between $\mathrm{M} 0$ and $\mathrm{M} 1$ was not (Fig. 2; Table I).

Phenotypic characterization of CTCs from patients of different subgroups. According to the EMT markers, the CTCs from patients with benign pulmonary and NSCLC were classified into three subpopulations: Epithelial $\left(\mathrm{E}^{+}\right)$, bi-phenotypic $\left(\mathrm{E}^{+} / \mathrm{M}^{+}\right)$and mesenchymal $\left(\mathrm{M}^{+}\right)$.

The mean numbers of CTCs of these three subpopulations $\left(\mathrm{E}^{+}, \mathrm{E}^{+} / \mathrm{M}^{+}\right.$and $\left.\mathrm{M}^{+} \mathrm{CTCs}\right)$ in patients with benign pulmonary diseases were $0.84 \pm 0.80,0.00 \pm 0.00$ and $0.00 \pm 0.00$, respectively. The mean numbers of CTCs of each subpopulation were demonstrated to be statistically higher in patients with NSCLC compared with patients with benign diseases $(2.47 \pm 2.67,3.53 \pm 5.97$ and $1.16 \pm 1.83$, respectively; $\mathrm{P}<0.05$; Fig. 1A; Table I).

The rate of $\mathrm{E}^{+} \mathrm{CTCs}$ in patients with benign pulmonary diseases was lower compared with that in patients with NSCLC [60.0 (15/25) and 67.1\% (57/85), respectively], but the difference was not significant. The $\mathrm{E}^{+} / \mathrm{M}^{+}$and $\mathrm{M}^{+} \mathrm{CTC}$-positive rates were significantly higher in patients with NSCLC $[75.3$ $(64 / 85)$ and $44.7 \%$ (38/85), respectively] compared with patients with benign pulmonary diseases $[0.0(0 / 25)$ and $0.0 \%$ (0/25), respectively] $(\mathrm{P}<0.05$; Fig. 2; Table I).

Comparing between patients with distant and non-distant metastasis, no significant difference was observed with regards to the numbers of $\mathrm{E}^{+}, \mathrm{E}^{+} / \mathrm{M}^{+}$and total CTCs, respectively $(\mathrm{P}>0.05)$. The number of $\mathrm{M}^{+}$CTCs was significantly higher in the M1 subgroup compared to the M0 subgroup (M1: mean, 

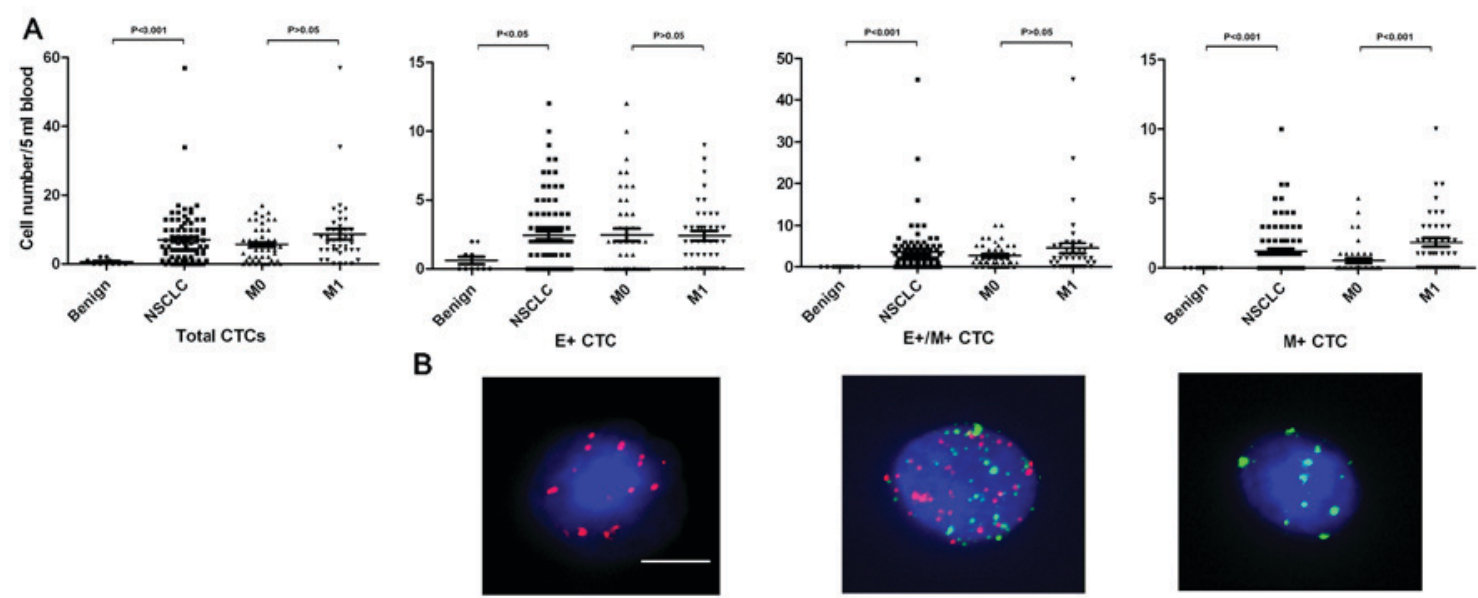

$\mathrm{E}+\mathrm{CTC}$

$E+/ M+C T C$

M+ CTC

Figure 1. Analysis of different phenotypic CTCs in blood samples from patients with benign disease or NSCLC with or without distant metastasis. (A) Dot plots presenting the number of total, $\mathrm{E}^{+}, \mathrm{E}^{+} / \mathrm{M}^{+}$and $\mathrm{M}^{+} \mathrm{CTCs}$ in patients with benign disease or NSCLC with or without distant metastasis. M0 indicates non-distant metastasis and M1 indicates distant metastasis. The lines inside the plots indicate the mean values. The error bars indicate the standard error of the mean. (B) Representative fluorescence images present RNA in situ hybridization of different phenotypic CTCs $\left(\mathrm{E}^{+}\right.$, $\mathrm{E}^{+} / \mathrm{M}^{+}$and $\left.\mathrm{M}^{+}\right)$. Scale bar, $10 \mu \mathrm{m}$. CTCs, circulating tumor cells; NSCLC, non-small cell lung cancer; $\mathrm{E}^{+}$, epithelial expressing; $\mathrm{M}^{+}$, mesenchymal expressing.
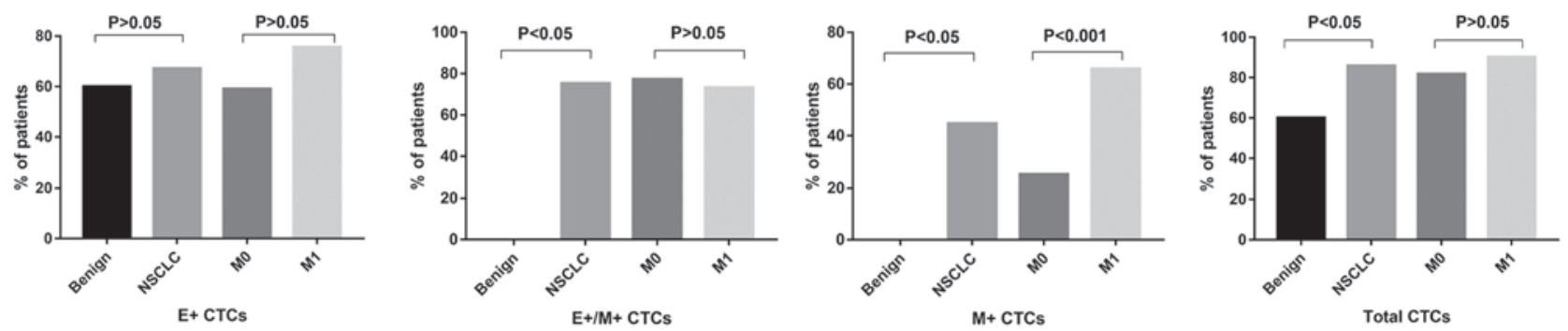

Figure 2. Percentages of patients with benign disease or non-small cell lung cancer in each subgroup with different phenotypic CTCs. CTCs, circulating tumor cells; $\mathrm{E}^{+}$, epithelial expressing; $\mathrm{M}^{+}$, mesenchymal expressing.

1.85 \pm 2.15 ; M0: mean, 0.52 $\pm 1.15 ; \mathrm{P}<0.001$; Fig. $1 \mathrm{~A})$. The rate of $\mathrm{M}^{+} \mathrm{CTC}$-positive patients was significantly higher in the $\mathrm{M} 1$ subgroup compared to the M0 subgroup [M1: $65.9 \%(27 / 41)$; M0: $25.0 \%$ (11/44); P<0.001; Fig. 2; Table I].

ROC curve and the optimal cut-off value. ROC curve analyses were performed to evaluate the diagnostic and predictive potential of the CTC populations. $\mathrm{E}^{+} / \mathrm{M}^{+} \mathrm{CTCs}$ displayed the highest AUC $[0.876 ; 95 \%$ confidence interval (CI), 0.814-0.939; $\mathrm{P}<0.001]$ compared with $\mathrm{E}^{+} \mathrm{CTCs}(0.672$; 95\% CI, 0.573-0.772), $\mathrm{M}^{+}$CTCs $(0.724 ; 95 \%$ CI, 0.629-0.818) and total CTCs $(0.830 ; 95 \%$ CI, 0.756-0.903) in discriminating patients with NSCLC and benign pulmonary diseases, with $\mathrm{P}<0.001$ (Fig. 3). The optimal cut-off value of $\mathrm{E}^{+} / \mathrm{M}^{+} \mathrm{CTC}$ was 1 , which indicated that patients with NSCLC exhibited $\mathrm{E}^{+} / \mathrm{M}^{+}$ CTCs and $\geq 1$ cell $/ 5 \mathrm{ml}$ blood. The sensitivity and specificity of this value were 75.29 and $100.00 \%$, respectively.

ROC curve and AUC analyses were conducted in order to distinguish NSCLC patients with distant metastasis from those with non-distant metastasis. $\mathrm{M}^{+} \mathrm{CTCs}$ exhibited the highest AUC value of 0.723 (95\% CI, 0.612-0.833; P<0.001; Fig. 4) compared with $\mathrm{E}^{+} \mathrm{CTCs}(0.541 ; 95 \% \mathrm{CI}, 0.417-0.665), \mathrm{E}^{+} / \mathrm{M}^{+}$ CTCs $(0.543 ; 95 \%$ CI, 0.410-0.658) and total CTCs (0.604; 95\% CI, 0.484-0.725). The optimal cut-off value of $\mathrm{M}^{+} \mathrm{CTCs}$ was 1 , which indicated that patients with NSCLC exhibit $\mathrm{M}^{+}$
CTCs and $\geq 1$ cell $/ 5 \mathrm{ml}$ blood. The sensitivity and specificity of this value were 65.85 and $75.00 \%$, respectively (Fig. 4).

Phenotypic characterization of CTCs in the cohort. The distribution of the three CTC subpopulations in patients with benign and NSCLC varied substantially (Fig. 5A). Among the patients with NSCLC, $31.8 \%$ carried all three phenotypic CTCs, $37.7 \%$ carried two types of CTCs $\left(25.9 \%\right.$ with $\mathrm{E}^{+}$and $\mathrm{E}^{+} / \mathrm{M}^{+} \mathrm{CTCs}$; $7.1 \%$ with $\mathrm{E}^{+} / \mathrm{M}^{+}$and $\mathrm{M}^{+} \mathrm{CTCs} ; 4.7 \%$ with $\mathrm{E}^{+}$and $\left.\mathrm{M}^{+} \mathrm{CTCs}\right)$ and $14.1 \%$ were CTC negative. Of the patients with benign disease, $40.0 \%$ were CTC negative and $60 \%$ exhibited $\mathrm{E}^{+}$CTCs. The patients with NSCLC with or without distant metastasis are presented in Fig. 5B. Among the NSCLC patients with distant metastasis, the majority were positive for all three subpopulations (46.3\%). Among the patients without distant metastasis, the majority exhibited $\mathrm{E}^{+}$and $\mathrm{E}^{+} / \mathrm{M}^{+} \mathrm{CTCs}$ (36.4\%; Fig. 5B).

\section{Discussion}

The important function served by the EMT phenotype has been demonstrated in lung cancer progression and drug resistance $(20,21)$. A previous study confirmed the capability of mesenchymal cells to escape from the primary tumor and reach distant sites (12). The clinical use of CTCs focusing on enumeration has been reported and validated by using the 




Figure 3. Receiver operating characteristic curve analyses of CTC subpopulations in patients with non-small cell lung cancer or benign disease. CTC, circulating tumor cell; $\mathrm{E}^{+}$, epithelial expressing; $\mathrm{M}^{+}$, mesenchymal expressing.

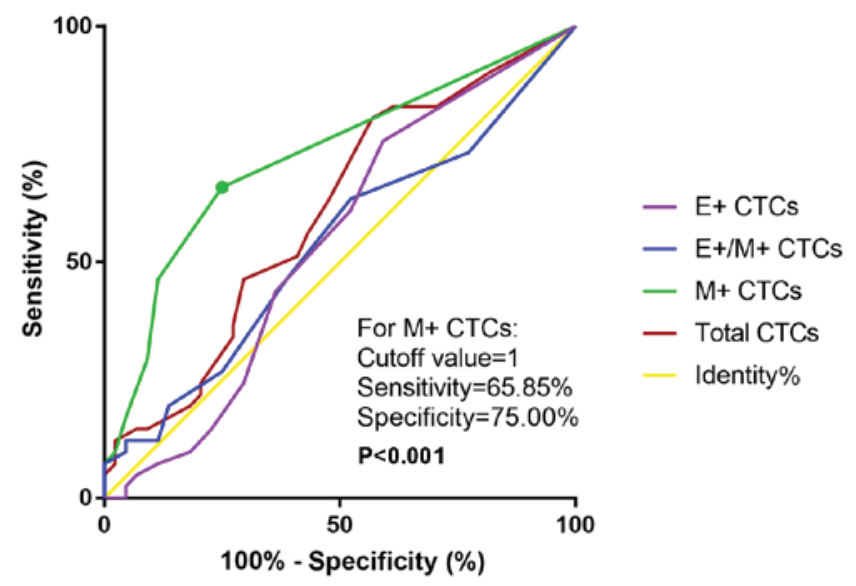

Figure 4. Receiver operating characteristic curve analyses of CTC subpopulations in patients with non-small cell lung cancer with or without distant metastasis. CTC, circulating tumor cell; $\mathrm{E}^{+}$, epithelial expressing; $\mathrm{M}^{+}$, mesenchymal expressing.

peripheral blood of patients with metastatic breast, prostate and colorectal cancer types $(22,23)$. However, there are few studies involving direct association analysis between EMT phenotypic CTCs and distant metastasis. Furthermore, there is a lack of a standard for the determination of CTCs in a clinical setting. A recent study has demonstrated that CTCs are able to express EMT-like phenotypes (24). Detection of the mesenchymal or hybrid EMT phenotype may be more informative for patients with aggressive disease subtypes or poor outcomes (25-29). Therefore, the application of novel technology to detect, capture and analyze the epithelial or mesenchymal subpopulations of CTCs is promising (30).

In the present study, the CTCs in a cohort of patients with NSCLC were characterized using a clinically feasible CTC assay with four epithelial markers, EpCAM and CK8/18/19, and two mesenchymal markers, vimentin and TWIST1, and the distribution and clinical value of CTCs with an EMT phenotype were studied. Vimentin is a highly conserved intermediate filament protein normally expressed in cells of mesenchymal origin, and its high expression is associated with a poor prognosis (31) and the occurrence of metastases (32) in patients with NSCLC. TWIST is a highly conserved basic helix-loop-helix transcription factor regulator of embryogenesis which is silent in most healthy adult tissues, and its overexpression in patients with NSCLC is involved in metastatic potential and poor survival $(33,34)$. Given the importance of vimentin and TWIST in the progression and prognosis of lung cancer, it is reasonable to select them as the marker for $M$ type CTCs in lung cancer. For the selection and validation of CTCs with epithelial and mesenchymal phenotypes, the use of members of CK, EpCAM, vimentin and TWIST1 families has become the standard method in patients with cancer (35). When epithelial cells start the procedure of EMT and progress into mesenchymal cells, the capacity for the invasiveness and metastasis of lung cancer is increased. Thus, the expression of epithelial cell markers including EpCAM and members of CKs are downregulated and that of mesenchymal cell markers is upregulated (14-16,35). Milano et al (36) designed a study to detect the EMT of CTCs in patients with metastatic NSCLC and analyzed the expression of epithelial markers (carcinoembryonic antigen-CK19), EMT-associated genes (vimentin) and EMT transcription factors (zinc finger protein SNAI2, zinc finger E-box-binding homeobox 1-2 and TWIST1-2) using a reverse transcription-polymerase chain reaction assay in order to calculate the cell numbers. However, in the present study, RNA in situ hybridization with a combination of epithelial (EpCAM and CK8/18/19) and mesenchymal (vimentin and TWIST1) markers were used to detect the epithelial and mesenchymal phenotype of CTCs, and an automated imaging fluorescent microscope was used to directly count the cells with different phenotypes. Furthermore, in the study by Milano et al (36), only 10 metastatic patients with NSCLC and 10 healthy volunteers were recruited to test the feasibility of CTC testing in the clinic. This previous study revealed that 3 of 10 samples were positive for CTCs at the baseline and the positive percentage of the patients increased subsequent to treatment with the platinum-based chemotherapy. During the dynamic testing, the expression of the mesenchymal phenotype appeared to be associated with a more unfavorable prognostic factor. However, the clinical significance of the EMT phenotypic CTC needs to be further validated considering the limited patient number in the study by Milano et al (36). In the present study, 110 patients ( 85 patients with NSCLC from different clinical stages and 25 patients with benign diseases) were recruited. The ROC curves revealed that $\mathrm{E}^{+} / \mathrm{M}^{+}$ CTCs display the highest AUC (0.876; 95\% CI, 0.805-0.948; $\mathrm{P}<0.001)$ in discriminating patients with NSCLC and benign pulmonary diseases. More importantly, it was revealed that the EMT expression of CTCs in patients is significantly associated with distant metastasis.

In the analysis of CTCs from the peripheral blood samples of patients in the present study, the number and incidence of total CTCs in patients with NSCLC and benign pulmonary diseases were compared. The distribution of the three distinct CTC subpopulations, namely $\mathrm{E}^{+}, \mathrm{E}^{+} / \mathrm{M}^{+}$and $\mathrm{M}^{+}$CTCs, were examined. The incidence and total number of CTCs were higher in patients with NSCLC compared with patients with benign pulmonary diseases. Furthermore, ROC curve analysis identified 1 unit of $\mathrm{E}^{+} / \mathrm{M}^{+} \mathrm{CTCs}$ as the optimal cut-off threshold with a sensitivity of $75.29 \%$ and specificity of $100 \%$ in distinguishing NSCLC from benign pulmonary 
A
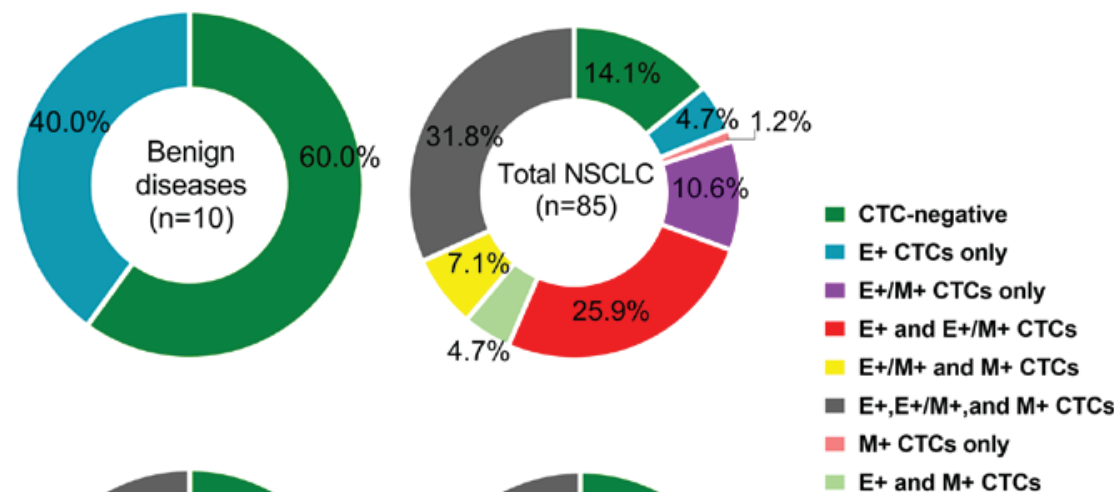

B
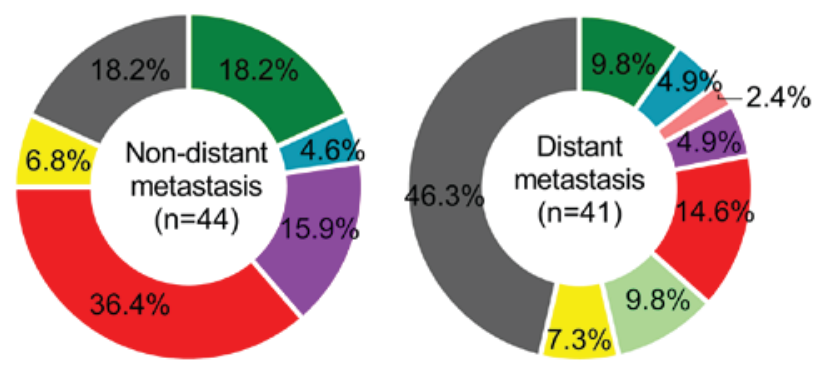

Figure 5. Distribution of CTC subpopulations in patients with benign disease or NSCLC with or without distant metastasis. Distribution of the three CTC subpopulations in (A) patients with benign and NSCLC and (B) patients with NSCLC with or without distant metastasis. CTC, circulating tumor cell; NSCLC, non-small cell lung cancer; $\mathrm{E}^{+}$, epithelial expressing; $\mathrm{M}^{+}$, mesenchymal expressing.

diseases. These results are consistent with those of previous studies in patients with breast cancer (14) and in cancer cell lines (35,37-39). Previous studies have described that the most notable challenge of CTC detection is the extremely low rate of CTCs, so the prognostic cut-off values were lowered (40-43). In a previous study by Chen et al (44), the optimal cut-off value in distinguishing patients with NSCLC from controls (healthy donors and benign diseases) was 8.93 units from the total number of CTCs with a sensitivity of $74.7 \%$ and specificity of $86.6 \%$. The inconsistency may be explained by the following reasons. First, the latter study detected the CTCs by folate receptor instead of EMT markers. Second, the number of CTCs was determined according to the quantity of folate receptor using a quantitative polymerase chain reaction assay, while in the present study, intact cells were captured using a pore-calibrated membrane and then characterized using the EMT markers. In addition, the EMT phenotype has also been observed and used as a marker for prognosis in other types of cancer, including breast cancer $(45,46)$, colorectal cancer $(47)$ and hepatocellular carcinoma (48).

Tumor dissemination usually occurs in a number of steps, including the generation of invasive cancer cells, dissolution of the stroma, intravasation into the peripheral circulation or lymphatic system, extravasation to the secondary lesions and angiogenesis at distal sites (9). This dynamic process has been hypothesized to transform cells with an epithelial phenotype into a mesenchymal type, and then result in the loss of adhesion between cells and the acquisition of enhanced motility, the recruitment of vasculature and resistance to apoptotic signals (30). In this process, the cellular cytoskeleton has been reported to be remodeled; the expression levels of CKs, which compose the epithelial cell cytoskeleton, decrease and those of vimentin, which compose the mesenchymal cell cytoskeleton, increase $(30,49,50)$. Based on several studies in human cancer cell lines and mouse models, the aberrant activation of the EMT phenotype has been implicated in the progression of metastasis $(15,49,51)$.

In order to extend the EMT analysis to CTC subpopulations in metastasis, the distribution of $\mathrm{E}^{+}, \mathrm{E}^{+} / \mathrm{M}^{+}$and $\mathrm{M}^{+}$ CTCs in patients with NSCLC with distant metastasis (M1) or without (M0) were detected and analyzed in the present study. Compared with patients with M0, the incidence and total number of $\mathrm{E}^{+} \mathrm{CTC}$ s were higher in patients with $\mathrm{M} 1$, but this difference was not significant. The differences in the total cell numbers and incidence of $\mathrm{E}^{+} / \mathrm{M}^{+} \mathrm{CTC}$ were also not significant. However, the incidence and number of $\mathrm{M}^{+} \mathrm{CTCs}$ were significantly higher in patients with M1 compared with patients with M0 $(\mathrm{P}<0.001)$. The results are consistent with the aforementioned theory of the EMT phenotype, suggesting an association between mesenchymal cells and cancer metastasis. In addition, a previous study reported that CTCs express the epithelial phenotype predominantly in the early stage of EMT, the epithelial and mesenchymal phenotypes in the intermediate stage and the mesenchymal phenotype in the last stage (14). The expression of EMT phenotypes in CTCs may function as a marker for the metastatic cascade, tumor dissemination and tumor progression (52). In the present study, the level of $\mathrm{M}^{+}$CTCs was substantially higher in the patients with distant metastasis, compared with the patients without distant metastasis. Furthermore, the results of the ROC curve and AUC analyses additionally demonstrate the predictive value of $\mathrm{M}^{+} \mathrm{CTCs}$. The optimal cut-off threshold in the diagnosis for NSCLC with distant metastasis compared with no distant metastasis was 1 unit with a sensitivity of $65.85 \%$ and specificity of $75.00 \%$, indicating that $\mathrm{M}^{+} \mathrm{CTCs}$ have an immense potential as a predictive factor for distant metastasis and tumor progression (14).

On the other hand, a number of studies have proposed a reversible EMT metastasis model, namely MErT, in which 
tumor cells activate EMT to invade and then undergo a reversion progress to form epithelial metastases once they arrive at distant sites $(11,15,30,53)$. Mesenchymal cells cannot easily be distinguished and the epithelial phenotype may be detected in the majority of metastatic lesions $(12,54)$. This dynamic progression may explain the proportions of all types of subpopulation presented in Fig. 5, of which $70.1 \%$ of M1 patients carried either $\mathrm{E}^{+} / \mathrm{M}^{+} \mathrm{CTCs}$ only or $\mathrm{E}^{+} / \mathrm{M}^{+}$CTCs accompanied with other phenotypic CTCs, and may be the reason why the numbers of $\mathrm{E}^{+}$ and $\mathrm{M}^{+}$CTCs were lower compared with that of the $\mathrm{E}^{+} / \mathrm{M}^{+} \mathrm{CTCs}$.

In summary, three CTC subpopulations $\left(\mathrm{E}^{+}, \mathrm{E}^{+} / \mathrm{M}^{+}\right.$and $\left.\mathrm{M}^{+} \mathrm{CTCs}\right)$ were detected and analyzed in blood samples from 110 patients in the present study using Canpatrol ${ }^{\mathrm{TM}} \mathrm{CTC}$ assays. The results demonstrate the predictive value of $\mathrm{E}^{+} / \mathrm{M}^{+} \mathrm{CTCs}$ in distinguishing patients with NSCLC from those with benign diseases, in addition to that of $\mathrm{M}^{+} \mathrm{CTC}$ in distinguishing patients with distant metastasis from those with non-distant metastasis. Although the role of EMT in metastatic progress remains controversial in different types of cancer, the results of the present study indicate the predictive value of the EMT phenotype of CTCs in peripheral blood, and it is a potential predictive biomarker for distant metastasis in patients with NSCLC.

\section{Acknowledgements}

Not applicable.

\section{Funding}

This study was supported by grants from the Projects of Medical and Health Technology in Zhejiang Province (grant no. N20090540), the Project of Zhejiang Provincial Administration of Traditional Chinese Medicine (grant no. 2016ZB069) and the Project of Clinical Scientific Research Fund of Zhejiang Medical Association (grant no. 2017ZXC-A13).

\section{Availability of data and materials}

The datasets used and/or analyzed during the current study are available from the corresponding author on reasonable request.

\section{Authors' contributions}

JiaZ and SZ contributed equally to the study concept and design. XZ and LW contributed equally to the clinical and experimental studies and writing of the article. JL collected the clinical data and JinZ performed the statistical analysis.

\section{Ethics approval and consent to participate}

The study was approved by the Ethics Committee of the First Affiliated Hospital of Zhejiang University (Hangzhou, Zhejiang, China). Written informed consent was obtained from the patients prior to enrollment.

\section{Patient consent for publication}

The patients provided written informed consent for the publication of any associated data.

\section{Competing interests}

The authors declare that they have no competing interests.

\section{References}

1. Siegel RL, Miller KD and Jemal A: Cancer statistics, 2018. CA Cancer J Clin 68: 7-30, 2018.

2. Chen W, Zheng R, Baade PD, Zhang S, Zeng H, Bray F, Jemal A, Yu XQ and He J: Cancer statistics in China, 2015. CA Cancer J Clin 66: 115-132, 2016.

3. Pécuchet N, Zonta E, Didelot A, Combe P, Thibault C, Gibault L, Lours C, Rozenholc Y, Taly V, Laurent-Puig P, et al: Base-position error rate analysis of next-generation sequencing applied to circulating tumor DNA in non-small cell lung cancer: A prospective study. PLoS Med 13: e1002199, 2016.

4. Shi ZM, Wang L, Shen H, Jiang CF, Ge X, Li DM, Wen YY, Sun HR, Pan MH, Li W, et al: Downregulation of miR-218 contributes to epithelial-mesenchymal transition and tumor metastasis in lung cancer by targeting Slug/ZEB2 signaling. Oncogene 36: 2577-2588, 2017.

5. Reka AK, Chen G, Jones RC, Amunugama R, Kim S Karnovsky A, Standiford TJ, Beer DG, Omenn GS and Keshamouni VG: Epithelial-mesenchymal transition-associated secretory phenotype predicts survival in lung cancer patients. Carcinogenesis 35: 1292-1300, 2014.

6. Frick MA, Kao GD, Aguarin L, Chinniah C, Swisher-McClure S, Berman AT, Levin WP, Cengel KA, DeCesaris C, Hahn SM, et al: Circulating tumor cell assessment in presumed early stage non-small cell lung cancer patients treated with stereotactic body radiation therapy: A prospective pilot study. Int J Radiat Oncol Biol Phys 102: 536-542, 2018.

7. Morbelli S, Alama A, Ferrarazzo G, Coco S, Genova C, Rijavec E, Bongioanni F, Biello F, Dal Bello MG, Barletta G, et al: Circulating tumor DNA reflects tumor metabolism rather than tumor burden in chemotherapy-naive patients with advanced non-small cell lung cancer: ${ }^{18} \mathrm{~F}-\mathrm{FDG}$ PET/CT study. J Nucl Med 58: 1764-1769, 2017.

8. Krebs MG, Sloane R, Priest L, Lancashire L, Hou JM, Greystoke A, Ward TH, Ferraldeschi R, Hughes A and Clack G, et al: Evaluation and prognostic significance of circulating tumor cells in patients with non-small-cell lung cancer. J Clin Oncol 29: 1556-1563, 2011.

9. Tsai JH and Yang J: Epithelial-mesenchymal plasticity in carcinoma metastasis. Genes Dev 27: 2192-2206, 2013.

10. Hanssen A, Loges S, Pantel K and Wikman H: Detection of circulating tumor cells in non-small cell lung cancer. Front Oncol 5: 207, 2015.

11. Yao D, Dai C and Peng S: Mechanism of the mesenchymal-epithelial transition and its relationship with metastatic tumor formation. Mol Cancer Res 9: 1608-1620, 2011.

12. Fischer KR, Durrans A, Lee S, Sheng J, Li F, Wong ST, Choi H, El Rayes T, Ryu S, Troeger J, et al: Epithelial-to-mesenchymal transition is not required for lung metastasis but contributes to chemoresistance. Nature 527: 472-476, 2015.

13. Zheng X, Carstens JL, Kim J, Scheible M, Kaye J, Sugimoto H, Wu CC, LeBleu VS and Kalluri R: Epithelial-to-mesenchymal transition is dispensable for metastasis but induces chemoresistance in pancreatic cancer. Nature 527: 525-530, 2015.

14. Zhang S, Wu T, Peng X, Liu J, Liu F, Wu S, Liu S, Dong Y, Xie S and Ma S: Mesenchymal phenotype of circulating tumor cells is associated with distant metastasis in breast cancer patients. Cancer Manag Res 9: 691-700, 2017.

15. Thiery JP: Epithelial-mesenchymal transitions in tumour progression. Nat Rev Cancer 2: 442-454, 2002.

16. Kalluri R: EMT: When epithelial cells decide to become mesenchymal-like cells. J Clin Invest 119: 1417-1419, 2009.

17. Amin MB, Edge S, Greene F, Byrd DR, Brookland RK, Washington MK, Gershenwald JE, Compton CC, Hess KR, Sullivan DC, et al: AJCC cancer staging manual. ed. 8 Cham. Switzerland: Springer 2017.

18. Wu S, Liu S, Liu Z, Huang J, Pu X, Li J, Yang D, Deng H, Yang $\mathrm{N}$ and $\mathrm{Xu} \mathrm{J}$ : Classification of circulating tumor cells by epithelial-mesenchymal transition markers. PLoS One 10: e0123976, 2015.

19. Fluss R, Faraggi D and Reiser B: Estimation of the youden index and its associated cutoff point. Biom J 47: 458-472, 2005. 
20. Kraljevic Pavelic S, Sedic M, Bosnjak H, Spaventi S and Pavelic K: Metastasis: New perspectives on an old problem. Mol Cancer 10: 22, 2011

21. Jin Y, Li F, Zheng C, Wang Y, Fang Z, Guo C, Wang X, Liu H, Deng L, Li C, et al: NEDD9 promotes lung cancer metastasis through epithelial-mesenchymal transition. Int J Cancer 134: 2294-2304, 2014.

22. Oakman C, Pestrin M, Bessi S, Galardi F and Di Leo A: Significance of micrometastases: Circulating tumor cells and disseminated tumor cells in early breast cancer. Cancers (Basel) 2: 1221-1235, 2010

23. Allard WJ, Matera J, Miller MC, Repollet M, Connelly MC, Rao C, Tibbe AG, Uhr JW and Terstappen LW: Tumor cells circulate in the peripheral blood of all major carcinomas but not in healthy subjects or patients with nonmalignant diseases. Clin Cancer Res 10: 6897-6904, 2004.

24. Bonnomet A, Brysse A, Tachsidis A, Waltham M, Thompson EW, Polette $\mathrm{M}$ and Gilles C: Epithelial-to-mesenchymal transitions and circulating tumor cells. J Mammary Gland Biol Neoplasia 15: 261-273, 2010 .

25. Nauseef JT and Henry MD: Epithelial-to-mesenchymal transition in prostate cancer: Paradigm or puzzle? Nat Rev Urol 8: 428-439, 2011.

26. Busch EL, Keku TO, Richardson DB, Cohen SM, Eberhard DA, Avery CL and Sandler RS: Evaluating markers of epithelial-mesenchymal transition to identify cancer patients at risk for metastatic disease. Clin Exp Metastasis 33: 53-62, 2016.

27. Tan TZ, Miow QH, Miki Y, Noda T, Mori S, Huang RY and Thiery JP: Epithelial-mesenchymal transition spectrum quantification and its efficacy in deciphering survival and drug responses of cancer patients. EMBO Mol Med 6: 1279-1293, 2014.

28. Raimondi C, Nicolazzo C and Gradilone A: Circulating tumor cells isolation: The 'post-EpCAM era'. Chin J Cancer Res 27: 461-470, 2015

29. Ferreira MM, Ramani VC and Jeffrey SS: Circulating tumor cell technologies. Mol Oncol 10: 374-394, 2016.

30. Lowes LE and Allan AL: Circulating tumor cells and implications of the epithelial-to-mesenchymal transition. Adv Clin Chem 83: 121-181, 2018.

31. Al-Saad S, Al-Shibli K, Donnem T, Persson M, Bremnes RM and Busund LT: The prognostic impact of NF-kappaB p105, vimentin, E-cadherin and Par6 expression in epithelial and stromal compartment in non-small-cell lung cancer. Br J Cancer 99: 1476-1483, 2008

32. Dauphin M, Barbe C, Lemaire S, Nawrocki-Raby B, Lagonotte E, Delepine G, Birembaut P, Gilles C and Polette M: Vimentin expression predicts the occurrence of metastases in non small cell lung carcinomas. Lung Cancer 81: 117-122, 2013.

33. Pallier K, Cessot A, Côté JF, Just PA, Cazes A, Fabre E, Danel C, Riquet M, Devouassoux-Shisheboran M, Ansieau S, et al: TWIST1 a new determinant of epithelial to mesenchymal transition in EGFR mutated lung adenocarcinoma. PLoS One 7: e29954, 2012.

34. Hui L, Zhang S, Dong X, Tian D, Cui Z and Qiu X: Prognostic significance of twist and N-cadherin expression in NSCLC. PLoS One 8: e62171, 2013.

35. Mirza S, Jain N and Rawal R: Evidence for circulating cancer stem-like cells and epithelial-mesenchymal transition phenotype in the pleurospheres derived from lung adenocarcinoma using liquid biopsy. Tumour Biol 39: 1010428317695915, 2017.

36. Milano A, Mazzetta F, Valente S, Ranieri D, Leone L, Botticelli A, Onesti CE, Lauro S, Raffa S, Torrisi MR and Marchetti P: Molecular detection of EMT markers in circulating tumor cells from metastatic non-small cell lung cancer patients: Potential role in clinical practice. Anal Cell Pathol (Amst) 2018 3506874, 2018

37. Houthuijzen JM, Daenen LG, Roodhart JM and Voest EE: The role of mesenchymal stem cells in anti-cancer drug resistance and tumour progression. Br J Cancer 106: 1901-1906, 2012.

38. Kitamura T, Qian BZ and Pollard JW: Immune cell promotion of metastasis. Nat Rev Immunol 15: 73-86, 2015.
39. Tripathi SC, Peters HL, Taguchi A, Katayama H, Wang H, Momin A, Jolly MK, Celiktas M, Rodriguez-Canales J, Liu $\mathrm{H}$, et al: Immunoproteasome deficiency is a feature of non-small cell lung cancer with a mesenchymal phenotype and is associated with a poor outcome. Proc Natl Acad Sci USA 113: E1555-E1564, 2016.

40. Lowes LE, Lock M, Rodrigues G, D'Souza D, Bauman G, Ahmad B, Venkatesan V, Allan AL and Sexton T: The significance of circulating tumor cells in prostate cancer patients undergoing adjuvant or salvage radiation therapy. Prostate Cancer Prostatic Dis 18: 358-364, 2015.

41. Lucci A, Hall CS, Lodhi AK, Bhattacharyya A, Anderson AE, Xiao L, Bedrosian I, Kuerer HM and Krishnamurthy S: Circulating tumour cells in non-metastatic breast cancer: A prospective study. Lancet Oncol 13: 688-695, 2012.

42. Lowes LE, Lock M, Rodrigues G, D'Souza D, Bauman G, Ahmad B, Venkatesan V, Allan AL and Sexton T: Circulating tumour cells in prostate cancer patients receiving salvage radiotherapy. Clin Transl Oncol 14: 150-156, 2012.

43. Meyer CP, Pantel K, Tennstedt P, Stroelin P, Schlomm T, Heinzer H, Riethdorf S and Steuber T: Limited prognostic value of preoperative circulating tumor cells for early biochemical recurrence in patients with localized prostate cancer. Urol Oncol 34: 235.e11-e16, 2016.

44. Chen X, Zhou F, Li X, et al: Folate Receptor-Positive Circulating Tumor Cell Detected by LT-PCR-Based Method as a Diagnostic Biomarker for Non-Small-Cell Lung Cancer. J Thorac Oncol 10: 1163-1171, 2015.

45. Franken B, de Groot MR, Mastboom WJ, Vermes I, van der Palen J, Tibbe AG and Terstappen LW: Circulating tumor cells, disease recurrence and survival in newly diagnosed breast cancer. Breast Cancer Res 14: R133, 2012.

46. Kasimir-Bauer S, Hoffmann O, Wallwiener D, Kimmig R and Fehm T: Expression of stem cell and epithelial-mesenchymal transition markers in primary breast cancer patients with circulating tumor cells. Breast Cancer Res 14: R15, 2012.

47. Yokobori $\mathrm{T}$, Iinuma $\mathrm{H}$, Shimamura $\mathrm{T}$, Imoto $\mathrm{S}$, Sugimachi $\mathrm{K}$, Ishii H, Iwatsuki M, Ota D, Ohkuma M, Iwaya T, et al: Plastin3 is a novel marker for circulating tumor cells undergoing the epithelial-mesenchymal transition and is associated with colorectal cancer prognosis. Cancer Res 73: 2059-2069, 2013.

48. Sun YF, Guo W, Xu Y, Shi YH, Gong ZJ, Ji Y, Du M, Zhang X, $\mathrm{Hu} \mathrm{B}$, Huang A, et al: Circulating tumor cells from different vascular sites exhibit spatial heterogeneity in epithelial and mesenchymal composition and distinct clinical significance in hepatocellular carcinoma. Clin Cancer Res 24: 547-559, 2018.

49. Kalluri R and Weinberg RA: The basics of epithelial-mesenchymal transition. J Clin Invest 119: 1420-1428, 2009.

50. Willipinski-Stapelfeldt B, Riethdorf S, Assmann V, Woelfle U, Rau T, Sauter G, Heukeshoven J and Pantel K: Changes in cytoskeletal protein composition indicative of an epithelial-mesenchymal transition in human micrometastatic and primary breast carcinoma cells. Clin Cancer Res 11: 8006-8014, 2005.

51. Yu M, Bardia A, Wittner BS, Stott SL, Smas ME, Ting DT, Isakoff SJ, Ciciliano JC, Wells MN, Shah AM, et al: Circulating breast tumor cells exhibit dynamic changes in epithelial and mesenchymal composition. Science 339: 580-584, 2013.

52. Kim MY, Oskarsson T, Acharyya S, Nguyen DX, Zhang XH, Norton L and Massagué J: Tumor self-seeding by circulating cancer cells. Cell 139: 1315-1326, 2009.

53. Chao Y, Wu Q, Shepard C and Wells A: Hepatocyte induced re-expression of E-cadherin in breast and prostate cancer cells increases chemoresistance. Clin Exp Metastasis 29: 39-50, 2012.

54. Gao D, Joshi N, Choi H, Ryu S, Hahn M, Catena R, Sadik H, Argani P, Wagner P, Vahdat LT, et al: Myeloid progenitor cells in the premetastatic lung promote metastases by inducing mesenchymal to epithelial transition. Cancer Res 72 : 1384-1394, 2012. 